\section{DIREITO}

V.8 • N.2 2020 - Fluxo Contínuo

ISSN Digital: 2316-381X

ISSN Impresso: 2316-3321

DOI: $10.17564 / 2316-381 X .2020 v 8 n 2 p 75-87$
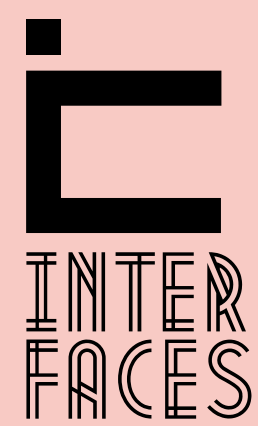

CIENTIFICAS

\title{
O SISU COMO POLÍTICA PÚBLICA DE ACESSO AO ENSINO SUPERIOR
}

SISU AS A PUBLIC POLLYY FOR ACCESS TO HIGHER EDUCATION

\section{SISU COMO POLÍTICA PÚBLICA DE ACCESO A LA EDUCACIÓN SUPERIOR}

Sammela Rejane de Jesus Andrade ${ }^{1}$

Artigo vinculado à tese intitulada Proficiência em leitura: acesso, permanência e sucesso na educação superior, desenvolvida no Programa de Pós-Graduação em Educação da Universidade Federal de Sergipe, sob orientação da Profa. Dra. Raquel Meister Ko. Freitag, com fomento de bolsa CAPES.

\section{RESUMO}

A oferta das vagas de acesso às universidades públicas brasileiras teve um aumento expressivo a partir do Sistema de Seleção Unificada (SISU), instituído em 2010 com a função de selecionar os candidatos para as vagas das instituições públicas utilizando a nota do Exame Nacional do Ensino Médio (ENEM) como principal fase, além de promover a reestruturação curricular do ensino médio e a mobilidade estudantil. Estas políticas não só ampliaram o número como também o acesso às vagas na educação superior, com a interiorização da rede de instituições de ensino superior e a implantação de bolsas de financiamento, como o FIES. Todavia, em se tratando de uma política pública voltada para a democratização, é preciso observá-la a partir de uma perspectiva mais ampla, não se restringindo apenas à ideia de acesso ao ensino superior, mas também no que tange à permanência e sucesso dos alunos participantes do novo processo de admissão. Diante disso, adotando as contribuições do policy cycle para a análise de políticas educacionais, discutimos a eficácia da política em questão quanto ao atendimento das metas propostas e alcançadas ao longo de sua existência. Entendendo a democratização como um processo que viabiliza a inserção do indivíduo no ambiente educacional e grarantido-lhe condições reais para isso, constatamos que o que foi assegurado aos candidatos às vagas do superior se caracteriza como uma maior oportunidade de competição devido ao aumento de número de vagas, porém, no que se refere às condições de permanência e conclusão dos cursos, ainda existe um longo percurso de mudanças educacionais efetivas a ser percorrido. 


\section{PALAVRAS-CHAVE}

SISU. Política Pública. Democratização. Educação Superior.

\section{ABSTRACT}

The offer of public universities to access vacancies increased significantly from the Unified Selection System - SISU, established in 2010 with the function of selecting candidates for vacancies of public institutions using the notes of the National Examination of Secondary Education - ENEM as a single phase, in addition to promoting the curricular restructuring of secondary education and student mobility. It is clear that the policies adopted by SISU and ESMS expanded access to university places. However, in the case of a public policy for democratization, we need to look at it from a broader perspective, not restricted to the idea of access to higher education, but also with respect to retention and student success participants of the new admissions process. Thus, adopting the contributions of the policy cycle for the analysis of educational policies through the Bobbio studies (2012), Parente and Matos (2011), Schimitz and Almeida (2011), among others, discuss the effectiveness of the policy as the meet the targets set and achieved over of its existence. Understanding democratization as a process that enables the insertion of the individual in the educational environment and giving him real conditions for this, we find that what was provided to job applicants from the top is characterized as a greater opportunity for competition because the number of increase vacancies, however, with regard to conditions of permanence and completion of the courses, there is still a long way from effective educational change to go.

\section{KEYWORDS}

SISU. Public Policy Democratization. College Education.

\section{RESUMEN}

La oferta de vacantes para acceder a las universidades públicas tuvo un aumento significativo con respecto al Sistema de Selección Unificado - SISU, establecido en 2010 con la función de seleccionar candidatos para vacantes de instituciones públicas utilizando el grado de Examen Nacional de Secundaria. - ENEM como fase principal, además de promover la reestructuración curricular de la escuela secundaria y la movilidad estudiantil. Es evidente que las políticas adoptadas a través de SISU y ENEM han 
aumentado el acceso a las plazas universitarias. Sin embargo, como es una política pública dirigida a la democratización, debe observarse desde una perspectiva más amplia, no solo restringiendo la idea de acceso a la educación superior, sino también con respecto a la permanencia y el éxito de los estudiantes participantes en el nuevo proceso de admisión. Ante esto, adoptando las contribuciones del ciclo de políticas al análisis de políticas educativas, a través de los estudios Bobbio (2012), Parente y Matos (2011), Schimitz y Almeida (2011), entre otros, discutiremos la efectividad de la política en cuestión con respecto a cumpliendo los objetivos propuestos y alcanzados durante su existencia. Entendiendo la democratización como un proceso que permite la inserción del individuo en el entorno educativo y dándole condiciones reales para esto, descubrimos que lo que se aseguró a los candidatos para las vacantes del superior se caracteriza por una mayor oportunidad de competencia debido al aumento en el número de estudiantes. Sin embargo, con respecto a las condiciones de permanencia y finalización de los cursos, todavía queda un largo camino de cambios educativos efectivos por cubrir.

\section{PALABRAS CLAVE}

SISU; Política pública; Democratización. Educación universitaria.

\section{INTRODUCÇÃO}

O Sistema de Seleção Unificada (SISU) tem como base legal de implementação nacional a Portaria Normativa $n^{0} 2$, de 26 de janeiro de 2010, que: - Institui e regulamenta o Sistema de Seleção Unificada, a Portaria Normativa n 21 , de 5 de Novembro de 2012 - Dispõe sobre o Sistema de Seleção Unificada e a Resolução n 25/2013/CONEPE - Estabelece os critérios para o ingresso nos cursos de graduação da Universidade Federal de Sergipe. Sua natureza de adesão das universidades é facultativa e tem como público-alvo os estudantes que queiram ingressar no ensino superior, conforme consta no Art. $2^{\circ}$ da Portaria Normativa n 21: “O SISU é o sistema por meio do qual são selecionados estudantes a vagas em cursos de graduação disponibilizadas pelas instituições públicas e gratuitas de ensino superior que dele participarem".

Os últimos dados divulgados pelo Inep, no Censo da Educação Superior de 2019, ajudam a compreender a importância que a política tem no que tange a oferta de vagas no ensino superior. Em todo o país, foram ofertadas, no ano de 2019, 235.476 vagas, em 129 instituições de ensino superior, públicas e particulares.

Todavia, a oferta de vagas e a promoção do acesso não são garantias para que a política púbica em questão seja satisfatória. Ao observar os números mais a fundo e em uma perspectiva temporal recente, é possível identificar o problema em torno da educação superior no Brasil.

Em 2003, o número de alunos que ingressaram na educação superior foi de 1.554.664, que, marcado por um incremento anual, ao longo de dez anos, chegou a 2.742.950 matrículas em 2013. Em contrapartida, o número de egressos não acompanhou esse crescimento, se mantendo em um estado 
de estagnação, o qual revela que, em 2003 apenas 34\% desses universitários conseguiram concluir a graduação, e, em 2013, a taxa cresceu apenas $2 \%$, atingindo a tímida marca de $36 \%$, que corresponde a 990 mil concluintes. A conta não fecha: ingressaram na educação superior, em 2013, 2.742 .950 alunos e saíram 990.000, valor muito próximo da saída em 2003.

A conta, continuando progressão temporal, também não fecha, a proporção de alunos que concluem os cursos de graduação continua sendo muito menor do que os que entram nas universidades: ainda segundo 0 Censo da Educação Superior, em 2018, mais de 3,4 milhões de alunos ingressaram em instituições de ensino superior. Desses, 580.936 mil em instituições públicas, enquanto o número de concluintes, no mesmo ano, foi de 1 milhão e 200 mil, dos quais, 259.302 mil são oriundos de estabelecimentos públicos de ensino.

Ao considerar que, em média, os cursos de graduação duram 5 anos, a estimativa de período de ingresso dos alunos concluintes em 2018 data do ano de 2014, quando ingressaram quase 3 milhões de estudantes. Haja vista o número de ingressantes ter aumentado significativamente e ele não ter ocorrido com o número de egressos, é preciso investigar quais são as causas para essa assimetria.

Se o número de concluintes não aumentou na mesma proporção que o número de ingressantes, é possível que somente a oferta e o acesso às vagas não é o suficiente; acende-se um alerta para a necessidade de criação e ampliação de políticas de permanência estudantil, uma vez que, em média, menos de $50 \%$ dos universitários concluem seus cursos de graduação.

Outros dados, divulgados pela Organização de Cooperação e Desenvolvimento Econômico (OCDE), por meio dos Relatórios Econômicos OCDE Brasil, ainda revelam que o número de brasileiros com ensino superior completo era em torno de 500 mil no ano de 2003. Após uma década, o número passou para cerca de $16 \%$ da população do país e em 2018, último levantamento, passou para $21 \%$. Houve um crescimento evidente, mas isso não impede que o brasil ainda continue com um índice muito distante da média os países pertencentes à OCDE, que é de $44 \%$.

Os números aqui apresentados demonstram que a ampliação do acesso à educação superior, tornando-a mais democrática, já é uma realidade no país, porém, quanto à efetividade da política, relativamente sem condições de permanência nos cursos e sua conclusão em período desejado, as expectativas não são atingidas.

Adotamos o conceito de Bobbio (2002), tendo em vista o problema aqui levantado e a necessidade de se discutir as políticas públicas educacionais do país, que define política pública como o conteúdo concreto e simbólico de decisões políticas para enfrentar um problema público, o presente artigo tem como objetivo discutir a trajetória do SISU como política pública para o acesso ao ensino superior no país, à luz do policy cycle, principalmente no que concerne às metas propostas e alcançadas desde a sua implementação até o presente momento.

\section{CAMPO DA POLÍTICA PÚBLICA}

Pensar em política pública se configura como um processo complexo que se inicia na definição dos termos, mais especificamente, na compreensão do termo política. Enquanto no Brasil a palavra 
"política" é utilizada de modo genérico e enquadra-se nos mais variados contextos, desde as disputas eleitorais, até as medidas governamentais voltadas para sociedade, em língua inglesa, existem três termos: polity, politics e policy, com definições e contextos de uso distintos. Para compreensão desses, adotamos a definição de Schmitz e Almeida (2011).

A Polity aborda as estruturas políticas, isto é, as instituições, normas e valores existentes no sistema político, o que pode ser exemplificado no país por meio da Constituição Federal. Já as Politics investigam os processos entre atores e interlocutores e suas relações entre si, que constituam a ordem política. Preocupam-se com questões sobre processos, como a participação, a solução de conflitos, as eleições e a legitimação, a exemplo dos processos eleitorais.

E por fim, a Policy, que tem como objetivo a dimensão do conteúdo da política, ou seja, é a operacionalização da política. Trata-se mais de gestão política do que do governo que a formulou. Nessa perspectiva o termo, política pública, aqui discutido está vinculado ao termo em inglês public policy, que significa o conteúdo simbólico da construção e atuação das decisões políticas.

Apesar de ser inegável a importância da compreensão e discussão crítica desse tipo de conteúdo, como um campo de estudo no meio acadêmico se configura como algo muito recente. Surgiu enquanto área de conhecimento e disciplina acadêmica nos EUA, com ênfase nos estudos sobre a ação dos governos.

O pressuposto analítico que regeu a constituição e a consolidação dos estudos sobre políticas públicas é o de que, em democracias estáveis, aquilo que o governo faz ou deixa de fazer é passível de ser (a) formulado cientificamente e (b) analisado por pesquisadores independentes. A trajetória da disciplina, que nasce como subárea da ciência política, abre o terceiro grande caminho trilhado pela ciência política norte-americana no que se refere ao estudo do mundo público. (SOUZA, 2006, p. 22).

Dessa forma, iniciou-se uma fase na qual os métodos científicos passam a ser aplicados nas formulações e aplicações das decisões governamentais, principalmente no que se refere aos problemas públicos. No Brasil, a análise de políticas e programas também tem se pautado no estudo de problemas públicos, principalmente no que permeia a avaliação e o monitoramento.

É importante elucidar que o campo de políticas públicas de um país abrange as mais diversas áreas de alcance social, a saber: saúde e segurança pública, por exemplo. Porém para discussão aqui feita, nos ateremos às políticas públicas educacionais, mais especificamente, política educacional para o acesso ao ensino superior.

No que se refere a definição do termo política pública, não existe uma única em voga. Alguns autores, a exemplo dos percussores dos estudos na área, assim o define:

Mead (1995) a define como um campo dentro do estudo da política que analisa o governo à luz de grandes questões públicas e Lynn (1980), como um conjunto de ações do governo que irão produzir efeitos específicos. Peters (1986) segue o mesmo veio: política pública é a soma das atividades dos governos, que agem diretamente ou através de delegação, e que influenciam a vida dos cidadãos. Dye (1984) sintetiza a definição de política pública como "o que o governo escolhe fazer ou não fazer". A definição mais conhecida continua sendo a de 
Laswell, ou seja, decisões e análises sobre política pública implicam responder às seguintes questões: quem ganha o quê, por quê e que diferença faz. (SOUZA, 2006, p. 24).

Assim, política pública, em linhas gerais, caracteriza as explicações em torno das decisões governamentais e seus reflexos sociais. Nessa perspectiva, emerge outro conceito, o de política social, caracterizada por Abranches (1998) como políticas que visam compensar outras políticas que colocam certos grupos em situação de dependência. Para Saviani (2007), a existência de política social sugere que as medidas oriundas das políticas vigentes não atendem ao bem-estar social.

Enquadra-se, então, as políticas educacionais como um tipo de política social, haja vista que dizem respeito às medidas que o Governo aplica para decidir o futuro da educação do país. Essas medidas, planejadas e executadas por meio de políticas públicas, podem ser de duas naturezas: Politica de Estado são aquelas que passam por instâncias diversas de discussão (congressos, fóruns etc.), são formuladas por meio de diferentes segmentos da sociedade, passam pelo congresso, baseiam-se em estudos técnicos e análises de impacto, efetivam-se por meio de leis, tem previsão orçamentária e, por isso, tem maiores chances de legitimação e continuidade.

Já a Política de Governo é aquela que o executivo formula e implementa diante de demandas internas e/ou externas (PARENTE; PEREZ; MATTOS, 2011, p. 18). 0 processo decisório normalmente é mais curto e se consolida no plano administrativo, sem um processo mais amplo de alternativas, escolhas e decisões coletivas.

Visto que a formulação e a aplicação de uma política podem ser de natureza do Governo ou do Estado, o que implica, principalmente, na legitimação e continuidade da mesma, ainda cabe evidenciar que existem três maneiras de efetivar sua visualização (PARENTE; PEREZ; MATTOS, 2011, p. 19). 0 plano é entendido como a soma/conjunto de programas que procura objetivos comuns; dispõe de ações programadas em uma sequência temporal, inclui estratégia, isto é, os meios estruturais e administrativos, assim como as formas de negociação, coordenação e direção.

Um programa é definido como um conjunto de projetos que persegue os mesmos objetivos, estabelece prioridades da intervenção; identifica e ordena os projetos, define âmbito institucional e aloca os recursos a serem utilizados. As organizações responsáveis pelos programas são predominantemente públicas. E o projeto é considerado como o planejamento que consiste no conjunto de atividades inter-relacionadas e coordenadas para alcançar objetivos específicos dentro dos limites de um orçamento e de um período definido.

A formulação de uma política voltada para atender às necessidades de um segmento da sociedade é um processo complexo, para o qual são necessários parâmetros balizadores para a avaliação dessas medidas adotadas, a fim de saber, entre outras coisas, se o objetivo de sua criação foi alcançado.

"A avaliação apresenta-se como análise dos dados e atribuição de um valor ao objeto avaliado, o que ajudará na tomada de decisão. Esse valor é uma construção social, que depende do usuário da avaliação e da situação da decisão" (SCHMITZ; ALMEIDA, 2011, p. 39). Sendo assim, a análise de uma política está voltada para a avaliação dos seus resultados e ajuda a identificar o seu sucesso ou fracasso.

Como parâmetros balizadores de avaliação podem ser utilizados três critérios: eficiência - medidas para a implementação de uma ação e os resultados alcançados, eficácia - relação entre as metas propos- 
tas e as metas alcançadas e efetividade - relação entre a implementação de uma política, seus produtos e seus resultados, além da comparação com políticas de mesma natureza para identificação da que apresentou melhor resultado (ARRETCHE, 2009). De maneira gradual, os três critérios podem ser vistos como meios de avaliação de maior ou menor complexidade de execução, em um movimento cíclico.

o policy cycle, ou ciclo de políticas, oriundo dos estudos americanos sobre o financiamento da máquina estatal, volta-se para a identificação dos processos de uma política, a fim de explicar as ações e/ ou interações ao longo do processo de criação, implementação e avaliação dela, por meio de etapas.

Figura 1 - Etapas do Policy cycle

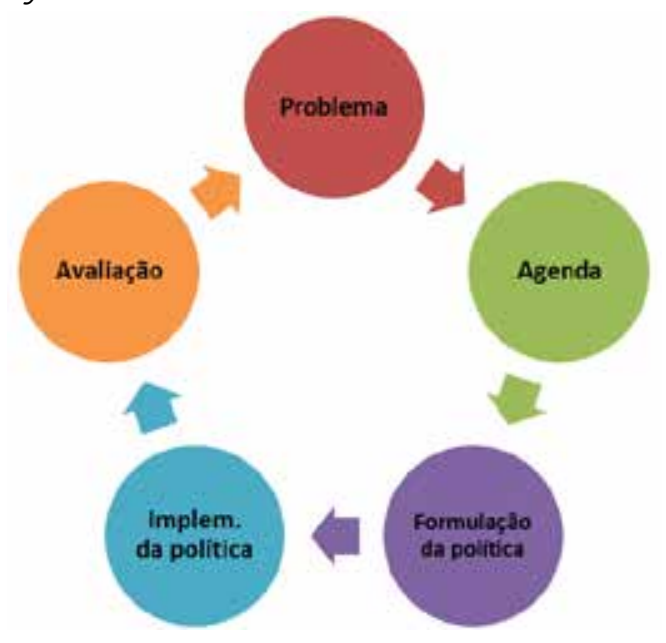

Fonte: Elaboração própria.

Toda a teoria de análise em torno do ciclo de políticas parte do estudo das etapas dessa política, iniciando-se com a construção ou elaboração da Agenda, primeira etapa que se caracteriza pela escolha de um determinado problema ou assunto, sua especificação e inclusão ou na lista de prioridades do governo. A segunda etapa é a Formulação da política, que se dá pelo processo contínuo de reflexão e pode ser visto como “diálogo entre as intenções e ações”. É a fase da elaboração do projeto propriamente dito, ou seja, é o momento em que um conjunto de dados, de informações relevantes combinadas com valores, ideais e princípios podem resultar e produzir um conhecimento, uma ação orientada.

Já a terceira etapa é a Implementação da política, momento em que a política entre em ação, ou seja, ao momento em que os programas e os projetos são implementados. Finalmente, a última etapa, Avaliação da política, fase que permite estabelecer uma relação de casualidade entre o objetivo e os resultados, ou seja, uma relação causal entre determinada modalidade de política pública e o sucesso ou fracasso na realização de seus propósitos.

A possibilidade de fazer a avaliação de uma política abre caminho para uma possível Reformulação dela, o que pode ser visto como mais uma etapa. Por meio da reformulação, a politica pode ser ajustada e reiniciar o seu ciclo, partindo de um problema que não foi sanado pela política na sua formatação anterior. 
De acordo com a teoria do ciclo da política pública, o caminho seguido começa com a elaboração de uma agenda, onde interesses e propostas são colocados na "mesa" de negociações, definindo-se preferências que são adaptadas ao projeto político governamental, seguido das etapas de formulação de propostas, escolha de alternativas e implementação das políticas públicas. (PINTO, 2008, p. 29)

Vejamos a aplicação do policy cycle no objeto em questão, tendo em vista que a proposta do presente trabalho é o tratamento do SISU como política pública educacional.

\section{o SISU como política pública}

A oferta das vagas de acesso às universidades públicas teve um aumento expressivo a partir do Programa de Apoio a Planos de Reestruturação e Expansão das Universidades Federais (REUNI) e do Sistema de Seleção Unificada (SISU), este instituído em 2010 com a função de selecionar os candidatos para as vagas das instituições públicas utilizando a nota do Exame Nacional do Ensino Médio (ENEM) como única fase e aquele um programa criado com a proposta de adotar medidas que garantissem o crescimento do ensino superior público.

Após anos de supremacia do acesso ao ensino superior por meio dos exames vestibulares, estes elaborados individualmente por cada instituição que ofertava vagas, o ENEM, após mudanças estruturais e de finalidade, passa a ser utilizado como exame de seleção de caráter nacional a partir de 2009. No ano seguinte, o governo federal cria uma plataforma de gerenciamento de dados, o SISU, que passaria a selecionar os candidatos por meio das notas obtidas pelo ENEM.

Art. $1^{\circ}$ O Sistema de Seleção Unificada - SISU, sistema informatizado gerenciado pela Secretaria de Educação Superior do Ministério da Educação, instituído pela Portaria Normativa MEC $n^{0} 2$, de 26 de janeiro de 2010, passa a ser regido pelo disposto nesta Portaria. Art. $2^{\circ} \mathrm{O}$ SISU é o sistema por meio do qual são selecionados estudantes a vagas em cursos de graduação disponibilizadas pelas instituições públicas e gratuitas de ensino superior que dele participarem.

$\S 1^{\circ} 0$ processo de seleção dos estudantes para as vagas disponibilizadas por meio do SISU é autônomo em relação àqueles realizados no âmbito das instituições de ensino superior, e será efetuado exclusivamente com base nos resultados obtidos pelos estudantes no Exame Nacional do Ensino Médio - ENEM. (BRASIL, 2012, p. 1).

A nova política pública para o acesso ao ensino superior surge a partir da necessidade de democratização do acesso, essa se daria por meio da nacionalização da prova, uma vez que os alunos poderiam concorrer, com uma única nota, a vagas de qualquer universidade pública do país inscrita no sistema de seleção. Além disso, outros objetivos da política são a reestruturação curricular do ensino médio e a mobilidade estudantil.

Proporcionar a concorrência de vagas em qualquer IES que aderisse ao Sistema de Seleção, possibilitando ao estudante realizar a prova no seu próprio estado e cidade, sem a 
necessidade exigida pelo vestibular tradicional, no qual era necessário o deslocamento até a cidade da instituição para realizar a prova. Com a mudança, criam-se oportunidades de concorrer a vagas, em nível nacional, o que de fato é a questão central do SISU, "a seleção nacional”. (LUZ; VELOSO, 2014, p. 74).

Os números aqui já discutidos apontam que as medidas propostas pela política foram significativas quanto à democratização do acesso às vagas, seja pela ampliação no número dessas, seja pelo sistema de nacionalização. Todavia, o problema do ensino superior no país ainda está longe de ser resolvido, uma vez que o número de candidatos que conseguem concluir os cursos após o ingresso ainda se encontra estagnado, o que acende um alerta vermelho. Se essa realidade continuar se perpetuando, o Brasil continuará muito distante da realidade de outros países quando o assunto é o número de cidadãos com diploma de graduação.

Ao também discutir essa problemática, Luz e Veloso (2014, p. 71) apresentam alguns apontamentos que ajudam a compreender melhor este cenário. O MEC por meio do documento de Proposta do ENEM e SISU argumenta que a nacionalização da prova é um benefício para os estudantes de baixa renda e que, além disso, aumentaria o acesso às vagas das universidades mais distantes dos grandes centros, contudo, as autoras apontam, "acreditamos que esse discurso é aparente, pois na essência desse novo processo de seleção ainda permanece o critério de seleção por meio da meritocracia. Sendo assim, a dinâmica de seleção permanece a mesma utilizada pelo vestibular".

Elas pautam essa afirmação no fato de que mesmo com a mudança do vestibular tradicional pelo ENEM, ainda se tem uma seleção pautada da captação dos melhores, daqueles que apresentam as melhores notas, deixando implícito que "os piores" ficarão de fora ou entrarão nas últimas vagas.

Segundo Halsey (1977 apud LUZ; VELOSO, 2014, p. 71), "é impossível que a meritocracia exista em uma sociedade desigual". 0 autor considera ainda que a "utilização do mérito individual como base para seleções justas seria possível de aplicação somente no futuro, já que a igualdade de fato entre os indivíduos também seria uma projeção, não podendo ser observada atualmente”.

A ideia de meritocracia e da seleção daqueles que têm os melhores desempenhos pode ajudar a discutir outra questão que aqui foi levantada como problema, a dificuldade de permanência nos cursos e sua conclusão. Haja vista que o SISU apresenta uma escala de grupos que concorrerão às vagas, esses que levam em consideração as políticas afirmativas, podendo essas serem de caráter racial (cotas), socioeconômico (renda familiar do candidato) e rede onde o candidato cursou a educação básica (pública ou particular).

A existência desses grupos possibilita selecionar os candidatos de acordo não só com a sua realidade educacional, mas também social, uma vez que é sabido que existe um abismo entre as escolas no país, sendo o próprio ranking divulgado anualmente pelo INEP, a partir do desempenho das unidades escolares no ENEM, uma forma de identificar. Porém, essa preocupação não vai além da etapa do ingresso, ao adentrar os muros da universidade, todos terão que cumprir as mesmas determinações pedagógicas.

Fica mais evidente vislumbrar essa realidade quando se observam as listas de chamada de excedentes do SISU em uma de suas edições, 2016, última edição do Enem que permitiu a utilização das notas obtidas no exame para certificação do ensino médio (BRASIL, 2017), na Universidade Federal 
de Sergipe, na qual cursos como Zootecnia, Engenharia Agronômica, admitiram alunos com médias 315,78 e 398,90, respectivamente.

Observe-se que a média está abaixo de 450 pontos, nota mínima para obtenção da certificação do ensino médio pelo Exame Nacional para Certificação de Competências de Jovens e Adultos (ENCCEJA). Quanto a diferença da média desses alunos e a nota de corte, para a mesma seleção, os candidatos que tentaram as vagas na primeira chamada do SISU, as médias foram de 595, 48 para o curso de Zootecnia e 587,08 para Engenharia Agronômica.

É importante elucidar que a proposta aqui não é tecer uma crítica às políticas afirmativas, mas problematizar a necessidade de ampliação da discussão, levando em consideração as questões pedagógicas em torno das etapas envolvidas, principalmente as provas do ENEM e as matrizes curriculares dos cursos superiores. E por ser uma discussão muito complexa, não haveria como abordá-la nesse espaço.

Levantada a questão norteadora da política aqui adotada, passaremos a enquadrá-la nos conceitos já mencionados.

\subsection{OBSERVAÇÃO DO SISU PELO POLICY CYCLE}

Ao analisar os conceitos básicos em torno das políticas públicas e levando em consideração o SISU como política pública educacional para o acesso ao ensino superior, é possível enquadrá-la como uma Política de Governo, haja vista ter sido instituída no governo Lula e mantida pelo governo Dilma como uma das medidas do processo de expansão e democratização do acesso ao ensino superior. Todavia, essa medida pode ser substituída por outra com a mesma finalidade.

Quando a sua visualização, trata-se de um Projeto vinculado ao programa REUNI, cuja finalidade é possibilitar maior democratização do acesso ao ensino superior, já a sua dimensão se enquadra como uma policy, uma vez que é uma política pública de decisão governamental.

Para realização de um enquadramento mais detalhado, apresentaremos o policy cycle do SISU.

O ciclo da política SISU tem início com o levantamento dos Problemas em torno do acesso ao ensino superior, entre eles, estão a dificuldade de deslocamento para fazer as provas dos vestibulares tradicionais, a necessidade de universalização e democratização do acesso. Na Agenda, é possível identificar os conflitos entre os que foram a favor e contra a substituição dos vestibulares tradicionais pelo ENEM e posterior adoção do SISU, ambas ocorridas no período de implementação do REUNI.

A formulação da política se deu pelo desenho administrativo feito por uma comissão, nesse caso, o Ministério da Educação. Em seguida a implementação da política se deu por meio das resoluções e portarias homologadas no ano de 2010 e sua posterior adoção pelas universidades e institutos federais.

No que se refere aos critérios de avaliação, adotamos o de eficácia, voltada para observação da relação entre meta proposta e meta alcançada. Sendo a meta primeira do SISU a universalização do acesso às vagas e, consequentemente, o aumento no número de oferta, é possível avaliá-la como uma política eficaz, haja vista os números aqui já apresentados. 


\section{CONCLUSÕES}

A proposta do presente trabalho foi, no escopo das políticas públicas educacionais para o acesso ao ensino superior, que atualmente no Brasil é materializada, principalmente, pelo SISU, problematizar o enquadramento da política objeto da análise em um policy cycle.

Nessa perspectiva, o SISU se revelou como uma política eficaz quanto ao atendimento de seu objetivo principal, porém foi evidenciado, também, que uma política voltada apenas para o acesso não ajuda na resolução, ou pelo menos, diminuição de problemas crônicos encontrados no ensino acadêmico do país.

Assim, é preciso a promoção de reformulação da política ou criação de políticas complementares que auxiliem nas questões de abandono e não conclusão dos cursos superiores em tempo hábil. Além disso, é pertinente a ampliação do estudo aqui realizado, com o objetivo de promover uma avaliação mais ampla, principalmente no que tange a eficiência e efetividade do SISU.

\section{REFERÊNCIAS}

ABRANCHES, Sérgio H. Política social, pobreza e desigualdade: a prática da teoria. In: ABRANCHES et al. Política social e combate a pobreza. Rio de Janeiro: Zahar, 1998. p. 9-31.

BRASIL. Ministério da educação. Portaria n⿳0 468, de 3 de abril de 2017. Dispõe sobre a realização do Exame Nacional do Ensino Médio - ENEM, e dá outras providências. Disponível em: http://portal. mec.gov.br/ultimas-noticias/212-educacao-superior-1690610854/47021-mec-estabelece-regraspara-a-realizacao-do-exame-em-2017. Acesso em: 10 jan. 2010.

BRASIL. Ministério da Educação. Secretaria de Educação Superior. Portaria n 2, de 26 de janeiro de 2010. Institui e regulamenta o Sistema de Seleção Unificada - SISU. Disponível em: http://portal. mec.gov.br/index.php?option=com_docman\&view=download\&alias=2704-sisuportarianormativa2\&l temid=30192. Acesso em: 6 out. 2019.

BRASIL. Ministério da Educação. Secretaria de Educação Superior. Portaria n⿳0 21, de 5 de novembro de 2012. Dispõe sobre o Sistema de Seleção Unificada - SISU. Disponível em: file:///C:/Users/User/ Downloads/Portaria\%20no\%2021-2012\%20.pdf. Acesso em: 6 out. 2019.

BRASIL. Conselho do Ensino, da Pesquisa e da Extensão da Universidade Federal de Sergipe.

Resolução n 25/2013/CONEPE. Estabelece os critérios para o ingresso nos cursos de graduação da Universidade Federal de Sergipe. Disponível em: http:// daffy.ufs.br/uploads/page_attach/ path/128/atos_da_reitoria_282.pdf. Acesso em: 6 out. 2019. 
BOBBIO, Norberto. Política. In: BOBBIO, Norberto; MATTEUCCI, Nicola; PASQUINO, Gianfranco. Dicionário de política I. 12. Ed. Brasília: Editora da UNB, 2002.

CENSO da educação superior. Disponível em: http://portal.inep.gov.br/web/guest/educacaosuperior. Acesso em: 3 jan. 2020.

LUZ, Jackeline Nascimento Noronha da; VELOSO, Tereza Christina Mertens Aguiar. Sistema de Seleção Unificada (SISU): refletindo sobre o processo de Seleção. Revista Educação e Fronteiras On-Line, Dourados-MS, v. 4, n. 10, p. 68-83, jan.-abr, 2014.

NOTAS da lista de excedentes UFS. Disponível em: http://sisu.ufs.br/uploads/content_attach/ path/12060/SUPLENTEES.pdf. Acesso em: 6 out. 2019.

NOTAS de corte da UFS. Disponível em: http://blogdoenem.com.br/ufs-notas-de-corte-sisu-2015/. Acesso em: 6 out. 2019.

PARENTE, Cláudia da Mota Darós; PEREZ, José Roberto Rus; MATTOS, Maria José Viana Marinho. Avaliação, monitoramento e controle social: contribuição à pesquisa e à política educacional. In: PARENTE, Cláudia da Mota Darós; PARENTE, Juliano Mota (Org.). Avaliação, política e gestão da educação. São Cristóvão: Editora UFS, 2011. p. 15-31.

PINTO, Isabela Cardoso de Matos. Mudanças nas políticas públicas: a perspectiva do ciclo de política. Rev. Pol. Públ., São Luis, v. 12, n. 1, p. 27-36, jan.-jun. 2008.

RELATÓRIOS Econômicos OCDE Brasil. Disponível em: http://www.oecd.org/economy/surveys/ Brazil-2018-OECD-economic-survey-overview-Portuguese.pdf. Acesso em: 2 jan. 2020.

SAVIANI, Dermeval. Da nova LDB ao FUNDEB: por uma outra política educacional. Campinas, São Paulo: Autores Associados, 2007.

SCHMITZ, Heike; ALMEIDA, Samantha Nunes de Oliveira. Avaliação de políticas e políticas de avaliação. In: PARENTE, Cláudia da Mota Darós; PARENTE, Juliano Mota (Org.). Avaliação, política e gestão da educação. São Cristóvão: Editora UFS, 2011. p. 32-46.

SOUZA, Celina. Políticas públicas: uma revisão da literatura. Sociologias, Porto Alegre, ano 8, n. 16, p. 20-45, jul.-dez. 2006. 


\section{(2) (1) (-)}

Este artigo é licenciado na modalidade acesso abertosob a Atribuição-Compartilhalgual CC BY-SA 